\title{
Humic acids from lignite. 2. Alkaline permanganate oxidation
}

\author{
Francisco Martin and Cesareo Saiz-Jimenez \\ Centro de Edafologia y Biologia Aplicada, C.S.I.C. . Aptdo. 1052, Sevilla, Spain \\ (Received 25 May 1977)
}

\begin{abstract}
The potassium permanganate oxidation of methylated humic acid from a Spanish lignite yielded mainly straight-chain alkanes together with a mix ture of fatty acids, methyl straight-chain alkyl ketones, aliphatic dicarboxylic, phenolic and benzenecarboxylic acids. Furthermore, some unusual compounds such as dehydroabietic and bromohydroxybenzoic acids and bis(2-ethylhexyl)phthalate were also identified. Although the analytical characteristics permit them to be included within the concept of humic acids, the oxidation products are closer to those from organic geochemical substances such as kerogen.
\end{abstract}

The term humic acids (HA) has been in recent years extensively used, arising from the imprecise definition 'those yellow to brown amorphous acidic substances extracted in alkaline media that precipitate upon acidification'. According to this definition, HA from various origins have been isolated.

The problem increases with the use of the parameters commonly applied to characterize them, like $\mathrm{C}$ and $\mathrm{H}$ contents, $E_{4} / E_{6}$ ratio, functional groups, i.r. and u.v. spectra etc., since with the same or similar values many natural and artificial substances extracted with alkali and precipitated in acid media are found.

Therefore other methods have been used to investigate the differences between HA from various origins or extracted by diverse agents. These methods have been mainly degradative, oxidative being in general more successful than reductive. Khan and Schnitzer ${ }^{1}$ have used the oxidation of methylated soil HA with potassium permanganate, making possible the isolation and identification of amounts of phenolic, benzenecarboxylic and fatty acids as well as alkanes and phthalates. Maximov et al. ${ }^{2}$ also applied this method to HA isolated from peats and lignites, and found among the degradation products basically benzenecarboxylic and aliphatic dicarboxylic acids. Ishiwatari ${ }^{3}$ by alkaline permanganate oxidation of sedimentary $\mathrm{HA}$ found straightchain and branched aliphatic and benzenecarboxylic acids, the yield of these latter being relatively high. Schnitzer et $a l^{4}$ also applied this method to the characterization of fungal HA. The major oxidation products were aliphatic mono- and dicarboxylic acids, being in this case similar to those from an arctic-soil $\mathrm{HA}$, where the ratio benzenecarboxylic:aliphatic acids is less than 1 , whereas in temperate soil HA (where the method has been extensively employed) the ratio ranged between 30 to 60 and higher.

In a first paper ${ }^{5}$ we reported the analytical characteristics and thermal degradation behaviour of HA extracted from a Spanish lignite. It was proved that there was no significant difference between IIA extracted by two alkaline agents and shown that the analytical data allowed them to be included within the concept of HA. In the present paper, to continue the characterization of lignite $\mathrm{HA}$, we have carried out the alkaline permanganate oxidation of one of the samples (HA L N) after methylation. In order to securc identification of the degradation products, these were studied in a combined system, gas chromatography-mass spectrometry-computer.

\section{EXPERIMENTAL}

The extraction procedure and characteristics of the HA have been previously reported ${ }^{5}$. Methylation of the sample was carried out with diazomethane. $1 \mathrm{~g}$ of the sample was suspended in $5 \mathrm{ml}$ of methanol and an excess of diazomethane was added. After standing for $24 \mathrm{~h}$ the ethereal solution was evaporated. This procedure was repeated three times.

Oxidation procedure was as follows: $0.5 \mathrm{~g}$ of the methylated sample was suspended in $40 \mathrm{ml}$ of a $2.5 \%$ solution of sodium carbonate and, under stirring and $\mathrm{N}_{2}$ atmosphere, $60 \mathrm{ml}$ of $4 \%$ potassium permanganate were added, keeping the reaction mixture at $90^{\circ} \mathrm{C}$ for $4 \mathrm{~h}$. After this time the reaction mixture was cooled, acidified with $2 \mathrm{~N} \mathrm{HCl}$, and the $\mathrm{MnO}_{2}$ residue was eliminated with sodium disulphite. The resulting yellow solution was exhaustively extracted (about $12 \%$ of total methylated) with ethyl acetate.

The ethyl acetate extract (after re-methylation) was separated by tlc on alumina (activated at $150^{\circ} \mathrm{C}$ for $18 \mathrm{~h}$ ) using a solvent system toluene:ethyl acetate $(3: 1)$. Four fractions were scraped out after visualization under u.v. light, but only that with $R_{f}$ between 0.55 and 0.80 gave a response in the gas chromatograph.

The gas chromatograph was a $5750 \mathrm{G}$ dual FID HewlettPackard instrument, fitted with a $3.05 \mathrm{~m} \times 3.2 \mathrm{~mm}(1 / 8 \mathrm{in})$ s.s. column packed with $3 \%$ OV -17 on Chromosorb W HMDS $80-100$ mesh, programmed from 90 to $300^{\circ} \mathrm{C}$ at a rate of $8^{\circ} \mathrm{C} / \mathrm{min}$. The mass spectrometer was an AEI MS 30 double-focusing instrument, coupled to a DS computer system. In this case the gas chromatograph was a Pye 104 with the same conditions as stated above.

Fractionation with solvent system was made according to Schnitzer and Khan ${ }^{6}$.

Air oxidation was made according to Wright and Schnit$\operatorname{zer}^{7}\left(170^{\circ} \mathrm{C}, 500 \mathrm{~h}\right)$. 


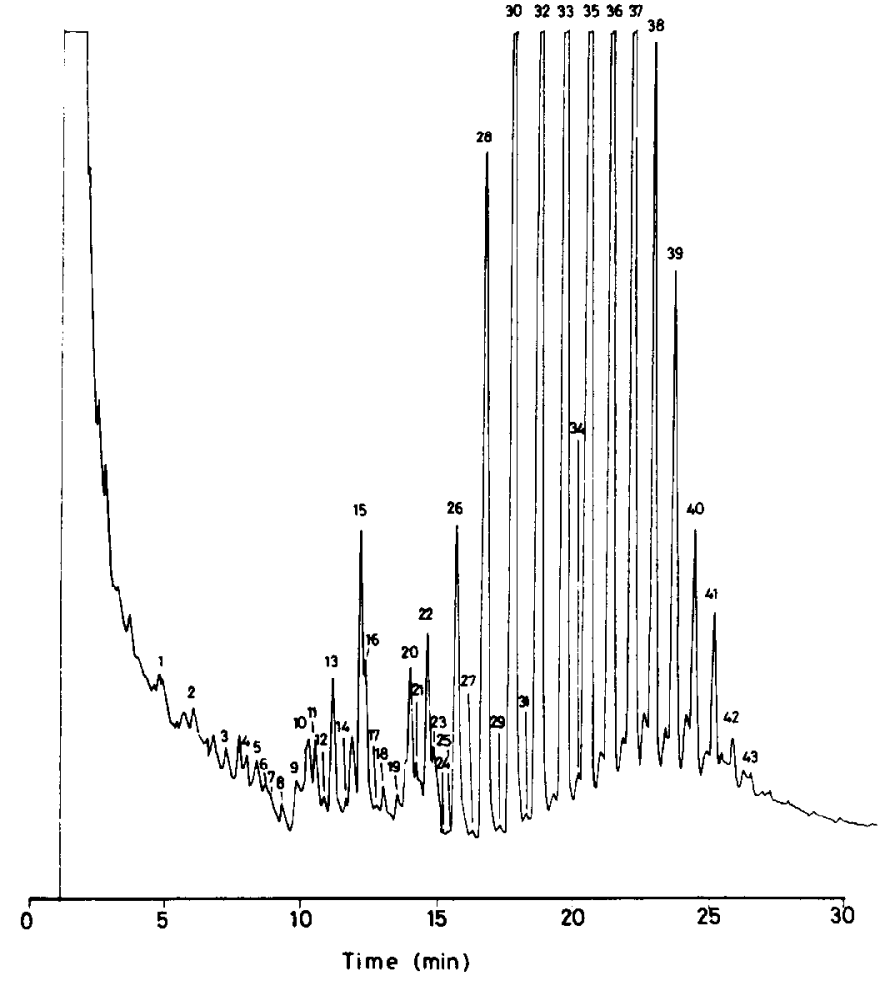

Figure 1 Gas chromatographic separation of oxidation products of methylated lignite HA. $2 \mu l$ from a $0.5 \mathrm{ml}$ solution

Table 1 Compounds produced by potassium permanganate oxidation of lignite HA (see Figures 1 and 3). (Alkanes and alkyls and fatty acids are straight-chain)

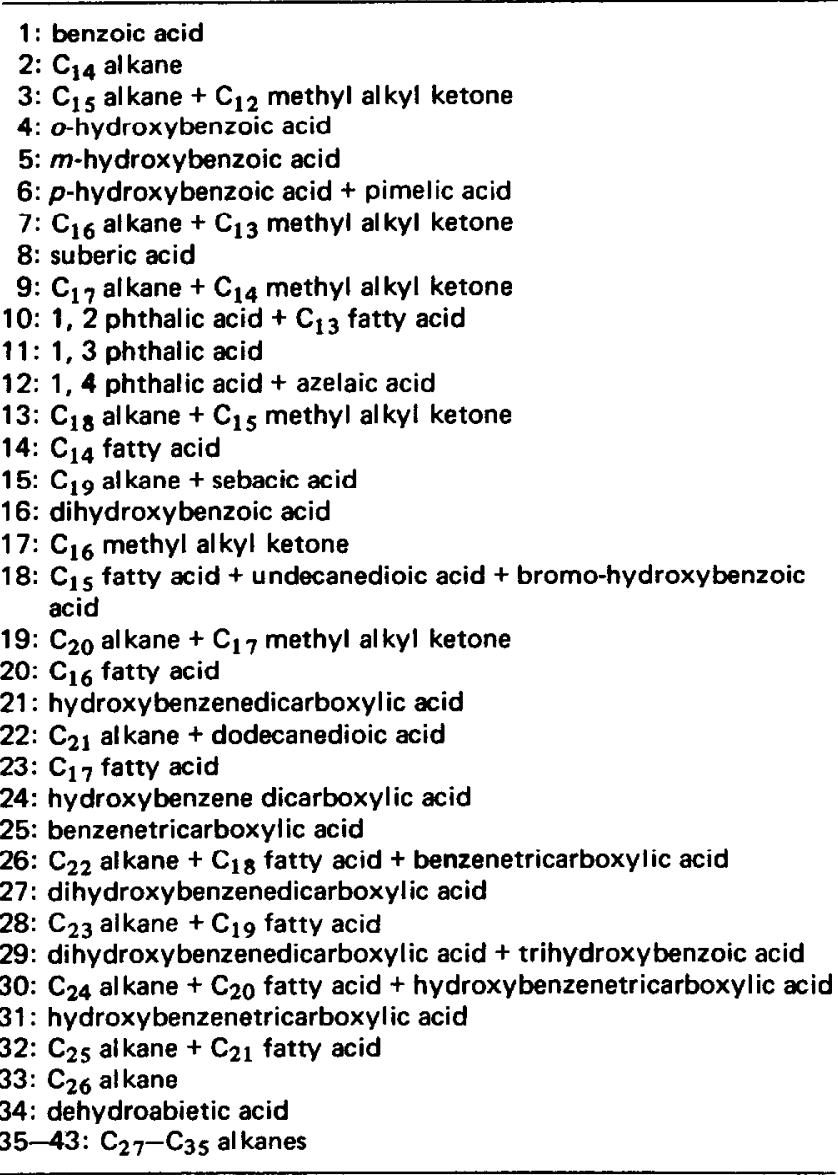

\section{RESULTS}

Figure 1 shows a chromatogram of the oxidized sample. It can be seen that the major peaks belong to a series. Table 1 shows the identified compounds. As the oxidation products have been methylated and the methoxyl content of the original sample is very low, they have been referred to as compounds with $\mathrm{COOH}$ and $\mathrm{OH}$ rather than esters and ethers. The isomers are listed without detailed substitution patterns, except for hydroxybenzoic and phthalic acids as the three isomers of each have been found.

The most abundant compounds belong to the straightchain alkane series from $\mathrm{C}_{14}$ to $\mathrm{C}_{35}$ representing between $\mathrm{C}_{22}$ and $\mathrm{C}_{33} 90 \%$ of the total oxidation products. The relative yields of the major alkanes were $\mathrm{C}_{27} \geqslant \mathrm{C}_{26}>\mathrm{C}_{25}>$ $\mathrm{C}_{28}>\mathrm{C}_{24}>\mathrm{C}_{29}$.

Palmitic acid (as ester) is the most abundant fatty acid and the yield is three times as great as that of stearic, the second in abundance. Phenolic and benzenecarboxylic acids (also as esters and ethers) represent less than $5 \%$ of the total compounds. Aliphatic dicarboxylic acids and methyl alkyl ketones are the minor compounds produced by permanganate oxidation.

In view of the high straight-chain alkanes content, the IIA was extracted with hexane, benzene and ethyl acetate according to Schnitzer and Khan ${ }^{6}$. The results are shown in Table 2. Ethyl acetate extracts the greatest amount before and after methylation whereas hexane and benzene extract almost the same quantity in toto.

After extraction the residual HA was oxidized. The yield of oxidation products was very poor. The chromatogram is shown in Figure 2 and the identified compounds are listed in Table 3. In this case the identification was focused only on the major peaks. These correspond to the most prominent fatty acids and to three other compounds, two of them not found among the oxidation products before extraction.

Figure 3 shows the chromatogram of the oxidation products obtained after air oxidation. The identified compounds are the same as those found before this treatment with the exception that dicarboxylic acids are not present

\section{DISCUSSION}

The alkaline potassium permanganate oxidation of methylated HA from soil of diverse origin yields mainly benzenecarboxylic and phenolic acids (Griffith and Schnitzer ${ }^{\circ}$ ). As far as we know the oxidation of methylated lignites HA has been reported only by Maximov et al. ${ }^{2}$ indicating also a predominance of aromatic over aliphatic compounds. Although the lignite under study was exhaustively extracted with a mixture ethanol:benzene $(1: 1)$ before extracting the $\mathrm{HA}^{5}$ to remove bitumen, the oxidation products are mainly

Table 2 Extraction of lignite HA with different solvents, as \% of original material (see Figure 2)

\begin{tabular}{lrr}
\hline & Before methylation & After methylation \\
\cline { 2 - 3 } Hexane & 0.12 & 1.34 \\
Benzene & 0.41 & 1.25 \\
Ethyl acetate & 18.88 & 11.43 \\
\hline
\end{tabular}




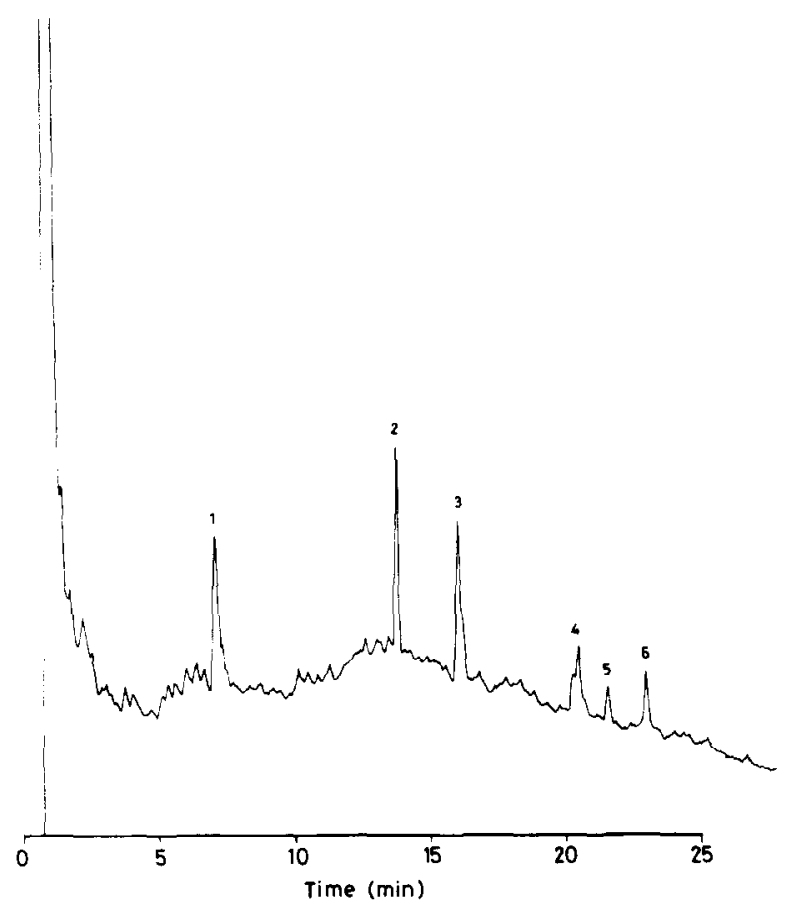

Figure 2 Gas chromatographic separation of oxidation products of methylated lignite $\mathrm{HA}$ after extraction with hexane, benzene and ethyl acetate. $2 \mu \mathrm{l}$ from a $0.1 \mathrm{ml}$ solution

Table 3 Compounds produced by potassium permanganate oxida tion of lignite HA after solvents extraction (see Figure 2)
1: benzaldehyde oxime
2: $\mathrm{C}_{16}$ fatty acid
3: $\mathrm{C}_{18}$ fatty acid
4: dehydroabietic acid
5: $N$-phenyl- $\beta$-naphthylamine
6: bis(2-ethyl hexyl)phthalate

constituted by aliphatic compounds and within these by straight-chain alkanes

These last have been reported to occur in soil $\mathrm{HA}^{9}$ in amounts between 0.01 and $0.37 \%$ and have also been found among the oxidation products of HA in minute amounts. In the HA under study, they constitute about $90 \%$ of the total oxidation products with a $\mathrm{C}$-odd to $\mathrm{C}$-even ratio of 1.07 which indicates a plant origin for the bulk of the alkanes.

Fatty acids occur in $\mathrm{HA}^{9}$ in a range within $0.14-9.8 \%$ and have also been found among the oxidation products, namely straight-chain $C_{16}$ and $C_{18}$. These were major fatty acids identified in lignite $\mathrm{HA}$, which suggest a biological origin. As Schnitzer and Neyroud ${ }^{9}$ pointed out fatty acids may be tightly retained as proved by the fact that after exhaustive extraction the above two are the prominent compounds found among the oxidation products.

Besides fatty acids, aliphatic dicarboxylic acids from pimelic to dodecanedioic have been identified. These acids are also found among the oxidation products of soil $\mathrm{HA}^{10}$ and lignites $\mathrm{HA}^{2}$ and possibly derive from long chains attached to an aromatic core ${ }^{11}$ since they disappear after prolonged air oxidation.

Methyl alkyl ketones from $C_{11}$ to $C_{20}$ were produced in small amounts. Morrison and Bick ${ }^{12}$ have isolated long-chain members from a garden soil and a peat ranging from $\mathrm{C}_{17}$ to $\mathrm{C}_{33}$. In our case these could be detected till $\mathrm{C}_{20}$ though the presence of higher ketones is highly probable. The GC-MS system, owing to the high alkane content (with an intense MS response), and the small amounts of methyl ketones (with very similar fragmentation pattern to alkanes) did not permit a conclusive identification of members higher than $\mathrm{C}_{20}$.

Abietic acid and various isomers constitute the main component of pine resins, resins that have been found in association with coal deposits ${ }^{13}$. Abietic acid after heating gives dehydroabietic acid, which is more stable and resistant to oxidation. Although this compound has been reported to be soluble in organic solvents, it is however one of those remaining after solvent extraction, which indicates, as for fatty acids, that it is tightly retained or that it is incorporated in the HA nucleus.

Benzenecarboxylic and phenolic acids are in this lignite HA minor compounds among the oxidation products. As happened with methyl alkyl ketones and probably straightchain fatty acids, higher substituted benzenecarboxylic and phenolic acids could not be detected by GC MS. However in the gas chromatogram (Figure 1) peaks whose $R_{f}$ values correspond to these series of compounds have been detected.

Bis(2-ethylhexyl)phthalate has been found in the lignite HA after solvent extraction, and though Khan and Schnitzer $^{14}$ have reported the presence of alkyl phthalates, we think that in our case this phthalate arises from the solvents, being firmly retained by the IIA matrix.

Bromo-hydroxybenzoic acid (bromine from typical MS fragmentation pattern) is an uncommon compound the presence of which cannot be explained, though Ogner ${ }^{11}$ found bromo derivatives among the oxidation products of nonhydrolysable humic residue from podzolic soil. Martín

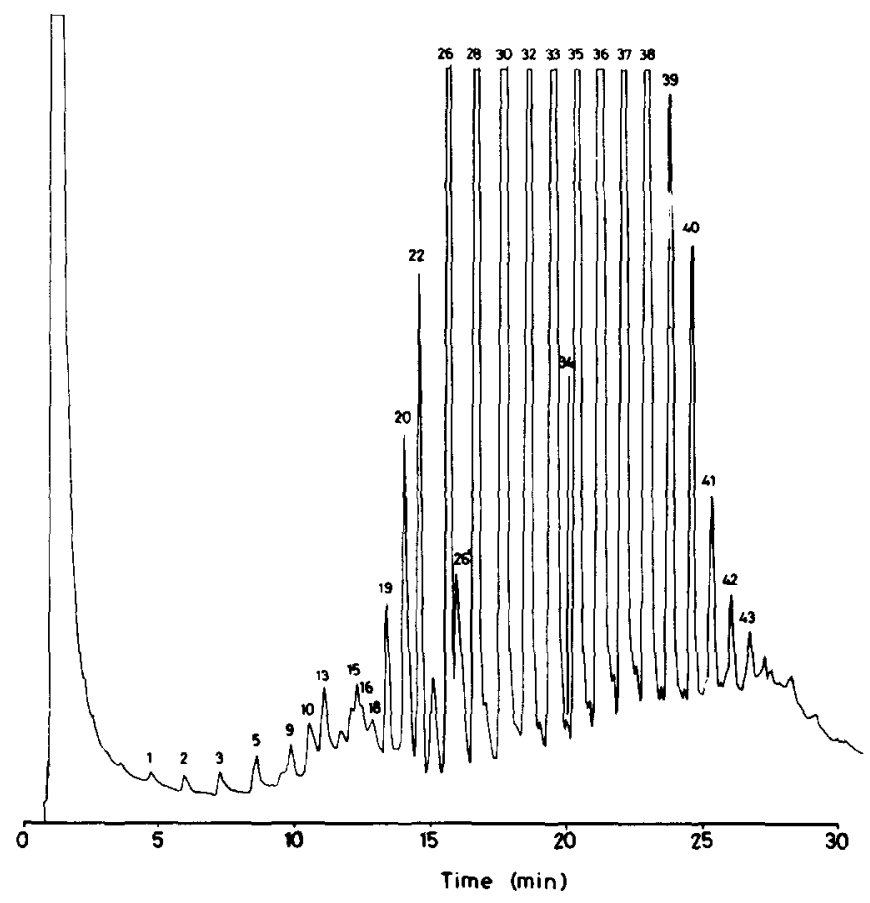

Figure 3 Gas chromatographic separation of oxidation products of lignite $\mathrm{HA}$ after $600 \mathrm{~h}$ air oxidation. $2 \mu \mathrm{l}$ from a $0.5 \mathrm{ml}$ solution. Peak 15 no sebacic acid; peak 18 no undecanedioic acid; peak 22 no dodecanedioic acid; peak $26^{\prime}$ a better separation of $C_{18}$ fatty acid 
et al. ${ }^{15}$ have also found bromomethane among the pyrolysis compounds of FA and HA from podzols.

Taking into account the yield of identified compounds, the aromaticity of this lignite HA calculated as

$$
\frac{\text { benzenecarboxylic }+ \text { phenolic }}{\text { total oxidation products }} \times 100
$$

must be very low. The aromaticity calculated according to Wright and Schnitzer ${ }^{7}$ was $68 \%$, in the same range as for HA from Chernozem, Solod and Solonetz soils ${ }^{6}$. Ishiwatari ${ }^{16}$ also by air oxidation found an aromaticity of $36 \%$ for a lake-sediment IIA and this value, according to this author, appears to be related to the nature of the material from which this HA may have originated.

However the above author found that the yield of benzenecarboxylic acids in the oxidation products is relatively high, assuming that the aliphatic compounds are considered to be less stable than aromatic ones. That depends on the nature of the aliphatic compounds and on the bond between them and the aromatics, since after $600 \mathrm{~h}$ of air oxidation of this lignite $\mathrm{HA}$, the oxidation products were constituted by the same compounds as before with the exception of dicarboxylic acids, which suggests that these acids may arise from methylene bridges or alicyclic hydrocarbons that are removed by air oxidation, while the other aliphatic compounds such as straight-chain alkanes, fatty acids, and methyl alkyl ketones are more stable, giving a value for aromaticity higher than that which is really correct.

\section{CONCLUSIONS}

According to the data presented in the first paper ${ }^{5}$ the HA extracted from this lignite has characteristics which permit it to be included within the concept of HA. This is indicated by i.r. and u.v. spectra, functional group content, $E_{4} / E_{6}$ ratio, Sephadex distribution, pyrolysis gas chromatography, etc. However the study of the potassium permanganate oxidation products of the methylated sample shows that the bulk of this HA is constituted by straight-chain alkanes together with a mixture of fatty acids, methyl alkyl ketones, aliphatic dicarboxylic, phenolic and benzenecarboxylic acids, which is in agreement not with the constitution reported for other humic acids but with that for organic geochemical substances such as kerogen.

\section{REFERENCES}

1 Khan, S.U. and Schnitzer, M. Can. J. Soil Sci. 1972, 52, 43

2 Maximov, O. B., Schapovalov, V. E. and Shvets, T. V. Fuel $1972,51,185$

3 Ishiwatari, R. Proc. Int. Mtg Humic Substances, Nieuwerluis 1972, Pudoc, Wageningen, 87

4 Schnitzer, M., Ortiz de Serra, M. I. and Ivarson, K. Soil Sci. Soc. Am. Proc. 1973, 37, 229

5 Martín, F. Fuel $1975,54,236$

6 Schnitzer, M. and Khan, S. U. Humic Substances in the Environment, Marcel Dekker Inc., New York, 1972

7 Wright, J. R. and Schnitzer, M. Nature 1961, 190, 703

8 Griffith, S. M. and Schnitzer, M. Can. J. Soil Sci. 1975, 55, 251

9 Schnitzer, M. and Neyroud, J. A. Fuel 1975, 54, 17

10 Schnitzer, M. and Wright, J. R. Trans. 7th Int. Congr. Soil Sci. $1960,2,112$

Ogner, G. Soil Sci. 1973, 116, 93

Morrison, R. I. and Bick, W. Chem. \& Ind. 1966, p 596

Thomas, B. R., in Organic Geochemistry, Springer Verlag, Heidelberg, 1969, Ch. 25, p 599

14 Khan, S. U. and Schnitzer, M. Geochim. Cosmochim. Acto $1972,36,745$

15 Martin, F., Saiz-Jimenez, C. and Cert, A. Soil Sci Soc. Am. J. 1977,41 , No. 6

16 Ishiwatari, R. Soil Sci. 1969, 107, 53 